\title{
Erratum to: Postural control in response to a perturbation: role of vision and additional support
}

\author{
Vennila Krishnan • Alexander S. Aruin
}

Published online: 12 August 2011

(C) Springer-Verlag 2011

Erratum to: Exp Brain Res (2011) 212:385-397

DOI 10.1007/s00221-011-2738-4

In the original publication of this article, the first name and the last name of the author Vennila Krishnan was interchanged. This is now corrected here.

The online version of the original article can be found under doi:10.1007/s00221-011-2738-4.

V. Krishnan · A. S. Aruin ( $\square)$

Department of Physical Therapy (MC 898),

University of Illinois at Chicago,

1919 W. Taylor St., Chicago, IL 60612, USA

e-mail: aaruin@uic.edu 